\title{
Socio-Economic Status and Health Shocks; Analysis of Coping Strategies Among Internally Displaced Persons (IDPs) Households in Abuja Nigeria.
}

Okpan Samuel ( $\sim$ okpansam@yahoo.com )

Evangel University, https://orcid.org/0000-0003-4685-5293

Peter Chukwumma Ezeah

Nnamdi Azikiwe University Faculty of Social Sciences

Research

Keywords: Internally Displaced Persons, Health shock, Coping strategies

Posted Date: December 17th, 2020

DOl: https://doi.org/10.21203/rs.3.rs-129343/v1

License: @ (1) This work is licensed under a Creative Commons Attribution 4.0 International License. Read Full License 


\section{Abstract}

Background: Internally Displaced Persons (IDPs) in Nigeria thrive on the livelihood that is dependent on primary activities, suffer constrained access to healthcare, with poor health outcomes. A situation which stems from income and socioeconomic status of the IDPs. This study investigated the various mechanisms adopted by IDP households in Abuja, Nigeria, in coping with adverse health events (health shocks) that have implications for their livelihood.

Methodology: The study used a mixed-method drawing on a quantitative structured questionnaire and semistructured interviews involving IDPs in Abuja Nigeria, to find out these coping mechanisms. The participants were recruited through convenience and purposive sampling techniques. Data were analyzed thematically.

Results: The findings show that the significant health shocks experienced by IDPs in Abuja, Nigeria were febrile illnesses such as diarrhoea (29.4\%), and post-traumatic stress disorder (PTSD) (18.8\%). The study equally observed that the IDPs are coping mainly through general contributions by themselves (48.5\%) and through utilization of traditional medicine (22.9\%). Another finding was that unclean toilets within the camp affect IDPs -especially women who are forced to adopt open defecation as an alternative toilet. Open defecation might expose them to other dangers such as rape.

Conclusion: Empirical sustainable public healthcare intervention focusing on primary and secondary healthcare that addresses the specific healthcare needs of IDPs in Nigeria should be provided to ameliorate their dire situation. Secondly, there is need to focus on sustainable economic empowerment programs such as improved farming mechanism, skill acquisition, education etc for the IDPs as such will consequently guarantee them better health care copping strategies.

\section{Introduction}

Conflicts and disasters often cause internal displacement. Large-scale displacement often leads to social destabilization. For instance, homes, religious system, political and economic destructions lead to new necessities among the displaced (Kett, 2005). Attempts at defining the term 'Internally Displaced Persons' (IDPs) throws up several complexes, interrelated issues. According to the Office of the High Commissioner for Human Rights, OHCHR, (2007) IDP's means

...persons who have been forced to flee their homes suddenly or unexpectedly in large numbers as a result of armed conflict, internal strife, systematic violations of human rights or natural or human-made disasters, and who are within the territory of their own country. (Office of the High Commissioner for Human Rights, OHCHR, 2007).

A Global Report on Internal Displacement (IDMC, 2018) shows that displacement resulting from conflict and violence in 2017 were estimated to about 11.8 million persons; this almost double 2016 figure of 6.9 million. Majority of these displacements occurred in Sub-Saharan Africa with a figure of 5.5 million, with the Middle East and North Africa about 4.5 million.

In recognition of the fact that an individual's health status is determined by numerous factors the World Health organization introduced the concept of "determinants of health" (The plight of IDPs are apparently dire due to 
their socio-economic status (Wilkinson and Marmot, 2003). Hanzhang, et al (2018), revealed that social factors can equally determine health status and outcomes; they identified social determinants to include a) social and economic environment comprising income, education; b) the physical environment comprising safe housing, sanitation and c) the individual's characteristics such as smoking, access to healthcare facilities. Evidence from studies suggests that IDPs are confronted with debilitating social status including lack of access to healthcare facilities (Olanrewaju et al, 2019). Similarly, Fineman, (2008) argued that IDPs are marginalized, disenfranchised, and disadvantaged from mainstream society).

The Global Survey estimated that of the 52 million non-refugee children affected by conflict, which includes but is not limited to IDPs, 24-26 million were in school and 25-28 million were out of school (Women's Commission for Refugee Women and Children; WCRWC 2004). However, that study has not been updated nor has its methodology been replicated. Godagama (2012) assessed the interventions channeled through the IDP camps in Mannar District, Sri Lanka using a mixed methodology consisting of both qualitative and quantitative methods. The findings indicate that the IDPs were primarily provided with basic requirements such as preschools (92\%), schools (72\%), and free books mainly by the GOs. IDMC (2008), found twelve countries where the majority of internally displaced children had no access to education during the 2008 school-year: Côte d'Ivoire, Democratic Republic of Congo, Guatemala, Indonesia, Iraq, Nepal, Nigeria, Philippines, Senegal, Somalia, Yemen, and Zimbabwe. It has also been reported that in various countries IDPs are paid lower wages than their counterparts in the general population. The average day rate for casual construction work in Goma, DRC, is normally $\$ 1.80$, but only $\$ 1.20$ for IDPs (Norwegian Refugee Council, NRC, 2014). Again, the poverty rate among IDPs has been estimated at 25 percent, compared with 20 percent for the general population (World Bank, 2011)

Despondently Nigeria has been finding it increasingly difficult and is almost failing in its task to manage its plethora of IDP predicaments (Olagunju, 2006). This situation portends danger for the citizenry and undermines the actualization of the Sustainable Development Goals (SDGs) number three which is on ensuring healthy lives and promoting well-being at all ages (United Nations, U.N., 2015). Scholars have identified a wide range of health shock among IDPs in Africa. In the region, the spectrum of health shocks includes stunting (38.6\%), underweight (28.4\%), and wasting (7.2\%) (Turnip, Klungsoyr, Hauff, 2010). In some IDP locations, diseases such as measles (20-30\%) and meningococcal meningitis (0.3\%) had been recorded (Santaniello-Newton and Hunter, 2000). Similarly, epidemics of cholera, yellow fever, and recently discovered hepatitis E (Nicole, 2015) reported in IDP and refugee camps across Africa. Besides, the U.N. Office for the Coordination of Humanitarian Affairs OCHA (2017) said that 6.1 million IDPs in Northeast Nigeria lack protection, 3.4 million in lack of adequate nutrition, 6.9 million lack access to health. OCHA (2017) also reported that, due to overcrowded settlements, IDPs in Nigeria suffer respiratory and other communicable diseases such as cholera and, diarrhoea, etc. outbreaks of tuberculosis, dysentery, and flu were reported in displacement camps in Myanmar (International Rescue Committee IRC. 2017).

Nevertheless, International Organization for Migration (2013) report suggest that IDPs are confronted with negative coping strategies to their health challenges. Geuken (2013) reasoned that coping strategies are ways individuals deal with anticipated or actual problems. Different types of psychological distress such as depression, anxiety, sleeplessness and other mental issues are usually identified as major health need of war and displaced persons (Roberts, Damundu, Lomoro, \& Sondorp, 2009). However, studies on IDPs coping 
mechanism mostly focus on general coping strategies to livelihood barriers by IDPs. For instance, The United Nations High Commission on Refugees, (2017) found that 35\% of IDPs in Host Communities in Yemen utilized child labour and $9 \%$ adopted child marriage as a coping mechanism. Similarly, Almedom, (2004), stated that IPDs cope by finding meaning or purpose to displacement and staying together. While Kassam and Nanji (2006), identified supporting-seeking as a coping strategy utilized by IPDs; and Ezard, Oppenheimer, Burton, Schilperoord, Macdonald, Adlekan, Ommeren, (2011) found that smoking hashish was commonly used by men, whereas tranquillizers were more likely to be used by women IPDs as a coping strategy. Studies on economic status as a determinant of coping mechanisms to healthcare shocks experienced by the IDPs are scarce. This paper, therefore, considered it pertinent to fill this gap by investigating the prevalent health shocks; coping mechanisms and influence of economic status on adopted coping mechanism among IDPs in Abuja, Nigeria. The remainder of this paper is divided into two sections-the first methodology used in data collection and analysis. The subsequent section presents the essential findings and classified according to two objectives developed from the data: health shocks, coping mechanisms to health shocks and influence of economic status on coping mechanism to health shocks. The paper then closes with a discussion of these findings.

\section{Hypothesis}

1. There is a significant relationship between IDPs economic status and coping strategies to health shocks experienced within IDPs camps, in Abuja Nigeria.

\section{Methods}

\section{Sample and Sampling Procedure}

The study was carried out in New Kuchinguro IDP camp Abuja, Nigeria, in 2019. The study adopted a mixed research design (Krol and Neri, 2009). The participants for the study were recruited among IDP residents in the camp, using convenience sampling (Atkinson \& Flint, 2001). Data collection for the study took place between July to October 2019. The researchers first introduced the investigation to the camp chairman and also sought his consent for the study. The camp chairman then nominated a research guide who served as an intermediary to identify available and willing camp residents. The criteria for participation were IDPs who are 18 years and above, and are residents in the camp for not less than three years and above. Ethical approval was gotten from respondents before administering the questionnaires, which was conducted by the researchers and intermediary. Three hundred and sixty-seven (130 males and 237 females) participants were recruited based on availability for the quantitative data, additional four ( 2 males and 2 females) were recruited (based on their administrative position) for the qualitative data. Written informed consent was obtained from those who accepted to participate in the study.

The study was reviewed and approved by Faculty of Social Sciences, Nnamdi Azikiwe University committee on theses approval. Written informed consent was obtained from those who accepted to participate in the study.

\section{Data Analysis}

The quantitative data were processed using the Statistical Package for Social Sciences (SPSS). Analyzed data are presented using descriptive statistical charts and tables with frequencies \& percentages. For the qualitative data, experts examined the data meticulously to guarantee systematic themes were drawn from the thoughts 
generated (Syed and Nelson, 2015). The transcripts were crosschecked and accommodated with the sound chronicles before being brought into NVivo 10 to analyze. Both the qualitative and quantitative data were triangulated.

\section{Results And Discussion}

\section{Socio-economic Attributes of Respondents}

This section presents the socio- demographic attributes of the respondents. The attributes are age, gender, marital status, employment statues, occupation, and annual income of respondents. 
Table 1

Distribution of respondents by socio-demographic characteristics

\begin{tabular}{|c|c|c|c|}
\hline Socio - Economic characteristic & Variables & Frequency (F) & Percentage (\%) \\
\hline \multirow[t]{7}{*}{ Age } & $14-20$ & 65 & 17.7 \\
\hline & $21-27$ & 76 & 20.7 \\
\hline & $28-34$ & 128 & 34.9 \\
\hline & $35-41$ & 33 & 9.0 \\
\hline & $42-48$ & 22 & 6.0 \\
\hline & 49 and Above & 43 & 11.7 \\
\hline & Total & 367 & 100 \\
\hline \multirow[t]{3}{*}{ Gender } & Male & 130 & 35.4 \\
\hline & Female & 237 & 64.6 \\
\hline & Total & 367 & 100 \\
\hline \multirow[t]{5}{*}{ Marital Status } & Single & 140 & 38.1 \\
\hline & Married & 195 & 53.1 \\
\hline & Divorced & 11 & 3.0 \\
\hline & Widow/Widower & 21 & 5.7 \\
\hline & Total & 367 & 100 \\
\hline \multirow[t]{4}{*}{ Employment Statues } & Employed & 17 & 4.6 \\
\hline & Unemployed & 265 & 72.2 \\
\hline & Unpaid family worker & 85 & 23.4 \\
\hline & Total & 367 & 100 \\
\hline \multirow[t]{6}{*}{ Occupation } & Paid employment/salaried & 17 & 4.6 \\
\hline & Farming & 153 & 41.7 \\
\hline & Entrepreneur/Artisan & 91 & 24.8 \\
\hline & Daily labour in Construction site & 74 & 20.2 \\
\hline & Manufacturing industry & 32 & 8.7 \\
\hline & Total & 367 & 100 \\
\hline \multirow[t]{3}{*}{ Annual Income as an IDP } & No Money & 66 & 18.0 \\
\hline & Below 25,000 & 154 & 42.0 \\
\hline & $25,000-49,999$ & 60 & 16.3 \\
\hline
\end{tabular}




\begin{tabular}{|llll|}
\hline Socio - Economic characteristic & Variables & Frequency (F) & Percentage (\%) \\
& $50,000-74,999$ & 55 & 15.0 \\
\hline $75,000-99,999$ & 22 & 6.0 \\
& 100,000 and Above & 10 & 2.7 \\
\cline { 2 - 2 } & Total & 367 & 100 \\
\hline
\end{tabular}

\section{Field survey: 2019}

Table 1 shows that majority of the respondents $128(34.9 \%)$ are aged between $28-24$ years while $22(6.0 \%)$ are aged $43-48$ years. The table also indicates that $237(64.6 \%)$ of the respondents are females while $130(35.4 \%)$ are males. The table shows that $195(53.1 \%)$ of the respondents are married while $11(3.0)$ are divorced. While $17(4.6 \%)$ are employed and $265(72.2 \%)$ are unemployed. In terms of occupational distribution, $153(41.7 \%)$ recorded as farmer while $32(8.7 \%)$ were employed in manufacturing industry. In terms of annual income $154(42.0 \%)$ of the respondents earn below 25,000 naira while $10(6.0 \%)$ earn above 100,000 naira.

\section{What are the healthcare shocks experienced by Internal Displaced Persons (IDPs) in Abuja, Nigeria?}

The study probed the major health shocks besetting IDPs in their camp. The respondents were asked what the major health shocks hampering their sustained healthcare livelihood are. The findings are presented in Table 1

Table 1

Prevalent health shocks

\begin{tabular}{|llll|}
\hline Variables & Prevalent health shocks \\
\hline Diarrhoea & Frequency (F) & Per cent (\%) \\
Cholera & 108 & 29.4 \\
Domestic Accidents & 49 & 13.4 \\
Malnutrition & 21 & 5.7 \\
Mental Health & 43 & 11.7 \\
Stunted Growth & 11 & 3.0 \\
\hline Post-Traumatic Stress Disorder (PTSD) & 22 & 6.0 \\
\hline Depression & 69 & 18.8 \\
\hline Total & 44 & 12.0 \\
\hline
\end{tabular}

\section{Field survey: 2019}

Table 1 shows that a majority of the respondents 108 (29.4\%) said that the major health shock to them within the camp is diarrhoea. At the same time, 11(3.0) identified mental disorder as a significant health shock to their healthcare livelihood within the camps. This implies that the IDPs are in dire need of environmental sanitation, clean water and counselling to improve upon health shocks such as diarrhoea, cholera, post-traumatic stress disorder (PTSD) which are most prevalent in the camps. Further explanations to this were captured in the IDI 
data which unveiled that the camps though have access to borehole water. The water is not treated nor appropriately channeled which makes it possible for pathogens to possibly contaminate the tanks causing consistent, diarrhoea and cholera; the prevalence of vector burn disease transmitted by mosquitoes etc. Again, the respondents stated that this disease could be as a result of lack of modern toilet system nor mechanized waste management system. An IDI respondent captured it thus:

First, it is nobody's responsibility to clean the camp that's why most times it is very unclean, though sometimes the women will sweep around it is not their responsibility or mandatory (Male, School teacher, 33 years old, New Kuchinguro camp).

A respondent stated thus:

Take a look at that my little daughter, she is the evidence of persistent Diarrhea in this camp as you can see, she is sick right now as you can observe her watery stool, most other kids are suffering from same thing. (Female, Food vendor, 32 years of age, New Kuchinguro Camp).

A male IDI respondent corroborating the view above revealed as follows;

You know mostly of the kids in this camp are suffering from diarrhea, we know easily because the kids defecate anywhere and mostly openly; but the that does not mean we adults are free from it. Most of the adults always complain of bloated belly and watery tool though we don't see their stool but we know it's true from the pain and inactivity they experience. There are several other illnesses we are battling with here everytime someone is always seeking.

Another IDI respondent stated as follows;

For me I think the major health situation we suffer most often is Cholera, especially the children and adults alike. There is no one in this camp that has not suffered from Cholera. Although we have water in the camp, but the water is not treated well for human intake. what I mean by treated is that you see the people handling the water themselves are not clean, the water tank which is hanged up there is very dirty. Sometime we see algae coming out of the tape. I don't know when last it was washed so is possible both the pipes and the tanks are contaminated or even due to lack of good control the people around contaminate the water (Male, Farmer,

\section{9 years old, New Kuchinguro camp)}

Another Respondent stated as follows;

Mama is afraid of meeting strangers that's what she is saying. I explained to her very well before she grudgingly agreed and she does not remember many things because of the shock she experienced during insurgency, which brought us here. She says, "Our major health shock is post-traumatic stress disorder. That traumatic experience is why some of us the elderly women avoid strangers; we were not like these before now. The attacks by Boko Haram was simply too much. I saw several dead bodies while trying to escape; the day my son was murdered I went into serious shock, I lost many friends and relatives, I don't seem to trust anyone except him my son." (Female, Farmer, 79 years old, New Kuchinguro camp)

Yet Another IDI respondent was very unsatisfied with the toilet system, she stated thus; 
Me I only use the bush to avoid infection, why I use the bush? Okay, that's because a church came last year and built a toilet, but it's a mess. Nobody washes it, and since it's just very few it can't serve everyone. Am certain using that toilet that's even when you can certainly expose one into disease? it is not clean at all. You know is own by everyone so nobody takes the responsibility of it. So, if you want to avoid all this disease's flying everywhere our people are suffering from every time better use the bush. The bush is risky, but sickness is worst, so I chose the less risk (Female, Jobless, 56 years old, New Kuchingoro Camp).

\section{What are the coping mechanisms to health shocks among Internal Displaced Persons (IDPs) in Abuja, Nigeria?}

The healthcare coping mechanism was explored by asking the respondents questions on how they cope. The findings are shown in Table 2,

Table 2

Composite Data on Healthcare Coping Strategies

\begin{tabular}{|c|c|c|c|}
\hline Items & Options & Frequency & Percentage \\
\hline \multirow[t]{7}{*}{ How do you Cope } & Contributions from relatives & 165 & 44.9 \\
\hline & Prayers & 56 & 15.3 \\
\hline & Chemist (Petty medicine dealers) & 33 & 8.9 \\
\hline & Donations from Agencies & 16 & 4.4 \\
\hline & Traditional medicine & 84 & 22.9 \\
\hline & Self-Help & 13 & 3.5 \\
\hline & Total & 367 & 100 \\
\hline
\end{tabular}

\section{Field survey: 2019}

Table 2 on respondents coping strategy shows that a majority of the respondents 178(48.5\%) cope through a general contribution from relatives, while 13(3.5\%) said they coped by themselves. Apart from general contribution praying for the sick was also identified. This implies that the respondents are highly religious and their religiosity perhaps solidifies communal leaving.

The qualitative data component affirmed the above, though with more insights. An IDI respondent indicated Although some people randomly come to help us cope with this predicament, we mostly cope with ourselves. Maybe they come once in a month is not regular and this is a place where people fall sick often. It is only the church and some NGO's. The government has abandoned us those once only know our existence during the election? Like the last election, they were coming even the Vice President came here but after election nothing. What do I mean by our self's? We help each other, like when someone is sick if we have money we can contribute and buy drugs for the person but when we don't have money, we leave the person. It is the will of God the person will survive; it is not the will of God then the person will go. Surviving and going are all the will of God. What I mean by going? Yes, that's death (Male, Farmer, 29 years old, New Kuchingoro camp).

Another IDI data corroborated the qualitative data on assistance by family and friend as a source of coping strategy as follows; 
Yes, for older women that are widows. She lives with her son that is not working, and we have different issues in the camp but we the youths that are mostly farmers, farming beans and corn contribute 10/50 naira for the treatment of old widows (Female. Widow/Jobless, 75 years old, New Kuchingoro camp).

\section{Test of Research Hypothesis}

1. There is a significant relationship between IDPs economic status and coping strategies to health shocks experienced within IDPs camps, in Abuja Nigeria.

\begin{tabular}{|c|c|c|c|c|c|c|}
\hline \multirow{3}{*}{$\begin{array}{l}\text { Coping } \\
\text { Strategy }\end{array}$} & \multicolumn{5}{|c|}{ Economic Status } & \multirow[t]{3}{*}{ Total } \\
\hline & Paid & Farming & Entrepreneur & Daily & Manufacturing & \\
\hline & Employment & & /Artisan & labour & & \\
\hline Contributions & $17(10.3 \%)$ & $148(89.7 \%)$ & $0(0.0 \%)$ & $0(0.0 \%)$ & $0(0.0 \%)$ & $165(45 \%)$ \\
\hline Prayers & $0(0.0 \%)$ & $5(8.9 \%)$ & $0(0.0 \%)$ & $51(91.1 \%)$ & $0(0.0 \%)$ & $56(15.3 \%)$ \\
\hline Chemist & $0(0.0 \%)$ & $0(0.0 \%)$ & $33(100 \%)$ & $0(0.0 \%)$ & $0(0.0 \%)$ & $33(9.0 \%)$ \\
\hline $\begin{array}{l}\text { Donations } \\
\text { from } \\
\text { Agencies }\end{array}$ & $0(0.0 \%)$ & $0(0.0 \%)$ & $7(43.8 \%)$ & $9(56.3 \%)$ & $0(0.0 \%)$ & $16(4.4 \%)$ \\
\hline $\begin{array}{l}\text { Traditional } \\
\text { medicine }\end{array}$ & $0(0.0 \%)$ & $0(0.0 \%)$ & $0(0.0 \%)$ & $65(77.4 \%)$ & $19(22.6 \%)$ & $84(22.9 \%)$ \\
\hline Self-Help & $0(0.0 \%)$ & $0(0.0 \%)$ & $0(0.0 \%)$ & $0(0.0 \%)$ & $13(100 \%)$ & $13(3.5 \%)$ \\
\hline Total & $17(4.6 \%)$ & $153(41.7 \%)$ & $40(10.9 \%)$ & $125(34.2 \%)$ & $32(8.7 \%)$ & $367(100 \%)$ \\
\hline
\end{tabular}

The table shows that economic status of the respondents affects their copping strategy to healthcare challenges $p=.000$.

\section{Discussion}

The study investigated the social economic status and health shocks of IDPs, analyzing their coping strategies in selected IDP camp within Abuja, Nigeria. Concerning health shocks, the study found that the major health shocks faced by IDPs in the study area are diarrhoea, post-traumatic stress disorder (PTSD), and cholera, which are attributable to lack of sustainable water sanitation and hygiene (WASH) mechanism prevalent in the camps. And also, as a result of the insurgency attacks experience by the respondents prior to their flights, many of them are consistently traumatized especially the women. The qualitative data corroborated this finding. By implication, lack of WASH facilities causes increased health shocks through the spread of diseases resulting in other possible challenges. For instance, due to the un-kept toilet system, some of the women lead to using the surrounding bushes for open defecation not minding they could be attacked raped or bitten by dangerous animals, thereby exacerbating their plight. This finding was validated by an empirical study conducted by Roberts, Odong, Browne, Ocaka, Geissler, Sondorp, (2009) in Northern Uganda, which discovered that malaria, fever/intestinal sickness, respiratory issues, were the three principles physical health challenge among the IDPs. 
Similarly, results from Sheikh, Mohammed, Agunbiade, Ike, Ebiti, Adekeye, (2014) demonstrated that the most widely recognized mental trauma experienced emanated from individual property lost. Their study further found that the chances of having PTSD were 3.5 occasions higher among the respondents with despondency and 3.7 incidents higher among the individuals who had seen the demise of a relative. Besides, the quantitative data showed that IDPs primary coping mechanism was through the contribution of money by relatives of the sick. While the qualitative data corroborated the finding, however, it revealed adverse inadequacies as they respondents stated that they could contribute 10 or 20 naira which in actual effect cannot purchase any meaningful form of healthcare for the sick. The implication is that many were left on their own without significant care. The study by Enwereji (2009) in Nigeria also found that there is no form of assistance from governmental authorities validates this finding.

The result of the Chi -Square test shows revealed a statistical significance between IDPs economic status and their copping strategy to healthcare challenges. This means that the job or employment of an IDP influence the nature of healthcare copping strategy such a person will access. The study found that IDP farmers copped through general contributions among themselves, while those employed as daily labourers copped through traditional medicine. It was also found that daily labourers had some of the worst healthcare coping mechanism those who don't use traditional medicine copped through prayers.

Entrepreneurs depends less on general contribution; perhaps their economic status may have improved considerably making it possible for them to fend for themselves through the patronizing petty medicine dealers (Chemist).

\section{Conclusion}

The study investigated the health shocks of IDPs, analyzing their coping strategies in New Kuchinguro IDP camp within Abuja, Nigeria. The study is limited by the location of the camp selected, and the sample size more generally. As such, the generalisability of the findings cannot be guaranteed. Again, the study covers only a camp located within the outskirts of the Federal capital territory of the country. There is a need for similar research to be conducted in other parts of Nigeria were IDP camps are located to obtain more empirical evidence. Despite these limitations, the study has provided some evidence regarding IDPs health shocks and their coping mechanism. The IDPs are indeed suffering from delirious illnesses, notably diarrhoea, posttraumatic stress disorder (PTSD), and cholera. Besides, it was found that the IDPs copped mainly by contributing money to help their sick. Due to lack of income as a result of their displaced status in most instances when there is no money to provide an infected person is prayed for and left to faith. There is a need for other studies to determine the mortality rate of IDPs. Despite the camp being located in Abuja, the Federal capital territory of Nigeria IDPs is still confronted with inadequate intervention by the government agencies, little assistance comes only from faith-based agencies perhaps to influence their religious choices. It is not enough to build a clinic; efforts should be made by the government, national and international humanitarian agencies to equip these clinics with drugs, bed space, functional pieces of equipment and stationed doctors and nurses. There is an urgent need for agencies to improve on inadequacies of healthcare coping systems in order to save lives. Intervention agencies need to take into consideration the gender of IDPs while designing a healthcare coping mechanism that improves the coping mechanism, especially for male IDPs. Public health measures which focus on the primary and secondary healthcare should be designed and implemented to assist the IDPs

Page $11 / 15$ 
here and other camps Nigerian. This may help to reduce the growing tendency of high mortality rate, despair and other health-related issues among IDPs in the country. Considering the fact that economic status of IDPs influence their healthcare copping mechanism, it is therefore imperative to empower the IDPs economically through skill acquisition, education and other forms of sustainable economic ventures as these will transcend into improved healthcare outcomes with less dependent on external sources.

\section{Declarations}

\section{Ethics approval}

School of Post graduate studies Nnamdi Azikiwe University, Awka, Anambra State (NAU/SPGS/4)

\section{Consent for publication}

Not applicable

\section{Funding}

This work did not receive any funding.

\section{Author contribution}

Okpan Samuel drafted the work and did data collection.

\section{Acknowledgement}

Not applicable

\section{References}

1. Adegbite, A. S. I. (2002). Psychological problems, support system and counselling needs of African refugees in Nigeria: Unpublished Doctoral thesis, Department of Guidance and Counselling, University of llorin, Nigeria.

2. Almedom, A. M. (2004). Factors that mitigate war-induced anxiety and mental distress. Journal of Biosocial Science, 36(4), 445-462.

3. Atkinson, R., \& Flint, J. (2001). Accessing hidden and hard-to-reach populations: Snowball research strategies. Social Research Update, 33, 1-4.

4. Bello, Dauod and Baig (2014) Coping strategies of Darfurians displaced women in Khartoum; Journal of Agricultural Extension and Rural Development,6(5), 168-174, 
5. Betancourt, T. S. and Khan, K. T. (2008). The mental health of children affected by armed conflict: Protective processes and pathways to resilience. International Rev Psychiatry. 20 (3): 317-328.

6. Burr, V. (2015). Social constructionism. London: Routledge.

7. Dada, F. M. (2006). Problems and coping strategies of institutionalized African refugees in Unpublished seminar paper, Department of Guidance and Counselling, University of Ilorin, Nigeria.

8. de Jong, J. T. V. M., \& Joop, M. (2002). Toward a culturally in-formed epidemiology: A pragmatic model for qualitative and quantitative psychiatric research in cross-cultural Transcultural Psychiatry, 39,422-433

9. Deng, F.M. (2000) Protecting the Dispossessed: A Challenge for the International Community. Brookings Institution Press.

10. Draughon, J. E. (2012). Sexual assault injuries and increased risk of HIV transmission. Adv Emerg Nurs 34:82-7.

11. Enwereji, E. E. (2009) Assessing Interventions Available to Internally Displaced Persons in Abia State, Nigeria. Libyan Journal OF medicine 4(1)23 - 26

12. Ezard, N., Oppenheimer, E., Burton, A., Schilperoord, M., Macdonald, D., Adlekan, M., Ommeren, M. (2011). Six rapid assessments of alcohol and other 383 substance use in populations displaced by conflict. Conflict and Health, 5(1), 1-15.

13. Folkman, S., \& Lazarus, R. S. (1991). Coping and emotion. In A. Monat \& R. S. Lazarus (Eds.), Stress and coping: An anthology (Vol. 3). New York, USA: Columbia University Press.

14. Galtung, J. (1978). Peace by Peaceful Means, Peace and Conflict Development and London: Sage Publication.

15. Gbakima, A., Richard, K., Namisa, K., and Foday, S. (2012) Sierra Leone journal of biomedical research nutritional status of children in displacement camps in Sierra Leone. Sierra Leone J Biomed Res; 4:22-31.

16. Getanda, E.M., Papadopoulos, C., and Evans, H. (2015) The mental health, quality of life and life satisfaction of internally displaced persons living in Nakuru County, Kenya. BMC Public Health; 15:755.

17. Geuken, J. (2013) Coping Strategies of internal refugees in Baku, Azerbaijan, A qualitative http://lup.lub.lu.se/student-papers/record/3629077

18. Guerrier, G., Zounoun, M., Delarosa, O., Defourny, I., Lacharite, M., and Brown, V., (2009). Malnutrition and mortality patterns among internally displaced and non-displaced population living in a camp, a village or a town in Eastern Chad.

19. Hamid, A. A. R. M, and Musa, S. A. (2010). Mental health problems among internally displaced persons in Darfur. International Journal of Psychology 45(4) 278-285

20. Ibeanu, O. (2015). Between Refuge and Right: Internally Displaced Persons and Inclusive Electoral Process in Nigeria. Lecture delivered at The Electoral Institute (TEI) Independent National Electoral Commission (INEC) Abuja, Nigeria. 
21. IDMC (International Displacement Monitoring Centre) (2018). Global Report on Internal The Internal Displacement Monitoring Centre 3 rue de Varembé, 1202 Geneva, Switzerland.

22. Inter-Agency Standing Committee (IASC) (2004) Guidelines on Mental Health and Psychosocial Support in Emergency Settings. http://www.humanitarianinfo.org/iasc/content/products

23. International Rescue Committee IRC. (2017) Refugees Compact; Addressing the Problem of Compacted Displacement. https://www.cgdev.org/sites/default/files/Refugee-Compacts- pdf

24. International Organization for Migration, (2013), Towards a fair deal for migrant workers in the global economy, ILO, Geneva, 2004, p.

25. Isah, B. S. (2015). Reproductive Health Challenges among Internally Displaced Persons in Abuja, Nigeria. A Research Project Submitted to the Department of Sociology, Faculty of Humanities and Social Sciences, Federal University, Oye-Ekiti, in Partial Fulfillment of the Requirement for the Award of Bachelor of Science (B.Sc) Hons in Demography and Social Statistics.

26. Kassam, A., \& Nanji, A. (2006). Mental health of Afghan refugees in Pakistan: A qualitative rapid reconnaissance field study. Intervention: International Journal Mental Health, Psychosocial Work \& Counselling in Areas of Armed Conflict, 4(1), 58-66.

27. Kellenberger, J. (2009). Root causes and Prevention of Internal Displacement: The ICRC Special Summit on Refugees, Returnees and IDPs in Africa, Kampala, Uganda; October 2009. International Committee on Red Cross (ICRC)

28. Kett M. (2005) Displaced populations and long term humanitarian assistance. BMJ; 331:98 -

29. Kim G, Torbay R, and Lawry L. (2007) Basic health, women's health, and mental health among internally displaced persons in Nyala Province, South Darfur, Sudan. Am J Public Health; 97:353-61.

30. Kroll, T. and Neri, M. (2009) Designs for Mixed Methods Research. 10.1002/9781444316490.ch3

31. Lanshie, W. N. E. and Henry B. Y. (2016) put the number of IDPs in north-eastern Nigeria at 3 million, the Internal Displacement Monitoring Centre (IDMC) estimated that there were approximately 2.2 million IDPs in Nigeria.

32. Marcus, S. (2010), Humanitarian financing and older people. (HelpAge) https://odihpn.org/magazine/humanitarian-financing-and-older-people/

33. Mooney, E. (2005). The Concept of Internal Displacement and the Case for Internally Displaced Persons as a Category of Concern. Refugee Survey Quarterly, 24(3), 9-26

34. Nicole W. (2015) The WASH approach: Fighting waterborne diseases in emergencies. Environ Health Perspect;123: A6-15.

35. Norwegian Refugee Council. IDMC. (2009) Global Overview 2015, People Internally Displaced by Conflict and Violence; 2015. 210-39.

36. Obi-Nwosu. H., Anazonwu. , Ifedigbo, C., \& Nweke, K., (2016). An Assessment of Symptoms of Distress among Internally Displaced Persons. Global Journal of Interdisciplinary Social Science 5(4):72-81 
37. OCHA (U.N. Office for the Coordination of Humanitarian Affairs) (2017) North east Nigeria Review: Basic Services Accessibility Atlas (Tool for Humanitarian, Recovery \& Development Interventions)'. Uganda: Information Management Unit, OCHA.

38. Olagunju, O. (2006). Management of Internal Displacement in Nigeria. PhD Dissertation in Legal Anthropology Brandeis University

39. Olwedo, M.A., Mworozi, E., Bachou, H., and Orach, C.G. (2008) Factors associated with malnutrition among children in internally displaced person's camps, Northern Uganda. Afr Health Sci; 8:244-52.

40. Owoaje, E. T., Uchendu, O. C., Ajayi, T. O. and Eniola, O. C., (2017). A Review of the Health Problems of the Internally Displaced Persons in Africa. Nigerian Postgraduate medical journal 23(4) 161 - 171

41. Roberts, B., Damundu, E., Lomoro, O., and Sondorp, E. (2009). Post-conflict mental health needs: a crosssectional survey of trauma, depression and associated factors in Juba, Southern Sudan. BMC psychiatry, $9(1), 7$.

42. Roberts, B., Odong, V.N., Browne, J., Ocaka, K.F., Geissler, W., and Sondorp, E. (2009) An exploration of social determinants of health amongst internally displaced persons in Northern Uganda. Confl Health;3:10.

43. Santaniello-Newton A, Hunter PR. (2000) Management of an outbreak of meningococcal meningitis in a Sudanese refugee camp in Northern Uganda. Epidemiol Infect; 124:75-

44. Sheikh, T. L., Mohammed, A., Agunbiade, S., Ike, J., Ebiti, W.N., and Adekeye, O. (2014) Psycho-trauma, psychosocial adjustment, and symptomatic post-traumatic stress disorder among internally displaced persons in Kaduna, Northwestern Nigeria. Front Psychiatry; 5:127.

45. Singh, K.P., Bhoopathy, S.V., Worth, H., Seale, H., and Richmond, R.L. (2016) Nutrition among men and household food security in an internally displaced person's camp in Kenya. Public Health Nutr; 19:723-31.

46. Siriwardhana C, Wickramage K. (2014) Conflict, forced displacement and health in Sri Lanka: A review of the research landscape. Conflict Health; 8:22.

47. Syed, M., \& Nelson, S.C. (2015). Guidelines for establishing reliability when coding narrative Emerging Adulthood, 3, 375-387. doi:10.1177/2167696815587648

48. Thomas, S. L. and Thomas, S.D.M (2004). Displacement and health. Department of War Studies, King's College London, London, UK and TDepartment of Forensic Mental Health Science, Institute of Psychiatry, London, UK

49. Turnip SS, Klungsøyr O, Hauff E. (2010). The mental health of populations directly and indirectly exposed to violent conflict in Indonesia. Conflict Health.

50. United Nations (2015). Sustainable Development Goals; "Goal 3: Ensure healthy lives and promote wellbeing for all at all ages" un.org/sustainable/development/health/

51. Vincent, M. and Sorensen, B. R. (2001) Caught Between Borders: Response Strategies of the Internally Displaced London and Sterling, VA: Pluto.

52. Wilkinson R, Marmot M. Determinants of Health the Solid Facts. World Health. 2003;2:1-33 Available from:http://www.euro.who.int/_data/assets/pdf_file/0005/98438/e81384.pdf. 